\title{
NEEDLE STICK INJURIES IN HEALTHCARE WORKERS OF A SECONDARY CARE HOSPITAL, PAKISTAN.
}

\footnotetext{
1. M.Phil (Biotechnology), MSc (Biotechnology)

Student

Quaid e Azam University Islamabad.

2. MBBS, MSPH

Medical Superintendent

DHQ Hospital Layyah.

3. MS Biotechnology, BS MLT Medical Laboratory Technologist DHQ Hospital Layyah.

4. BDS, MSc, DCPS, MSPS, MPH Associate Professor

Quaid e Azam Medical College Bahawalpur

5. BDS, M.Phil (Public Health), M.Phil (Oral Pathology) de' Montmorency College of Dentistry Lahore.

6. MSPH, BS Hons. Emergency and Intensive care sciences Emergency Medical Technologist DHQ Hospital Layyah.
}

Correspondence Address:

Dr. Muhammad Hashim Raza

Department of Pathology

DHQ Hospital Layyah.

hashim.msbt247@iiu.edu.pk

Article received on:

17/04/2019

Accepted for publication:

$13 / 12 / 2019$
Sahrish Khan ${ }^{1}$, Atiq-ur-Rahman², Muhammad Hashim Raza ${ }^{3}$, Muhammad Safdar Baig ${ }^{4}$, Faiz Rasul ${ }^{5}$, Muhammad Imran ${ }^{6}$

ABSTRACT... Needle Stick Injury (NSI) is a percutaneous piercing wound typically dealing with sharps. Needle stick injuries are the most common health care workers issue worldwide. The causes include various factors like type and design of needle, recapping activity, handling/ transferring specimens, collision between HCWs or sharps, during clean-up, manipulating needles in patient line related work, passing/handling devices or failure to dispose of the needle in puncture proof containers. NSIs may transmit other bacterial, fungal, or viral infections, including blastomycosis, cryptococcosis, diphtheria, herpes, malaria, mycobacteriosis, spotted fever and syphilis. Objectives: To determine frequency of needle stick injury among health care workers. Study Design: Cross-sectional study. Setting: District Headquarter Hospital Layyah. Period: Jan to March 2019. Material \& Methods: Sample size was 161. A structured pre-tested questionnaire containing both open and close-ended questions was administered during the period of Jan-March 2019. Results: Out of 161 participants, 114 (70.8\%) reported having a needle stick injury at least once during their clinical practice and the frequency of NSIs was significantly higher among nurses $(76.7 \%)$ as compared to Doctors $(50 \%)$, Laboratory staff $(45.5 \%)$ and waste handlers $(70.8 \%)$. Conclusion: Study concludes that in absence of the routine collection of accurate data on NSIs, small studies have been useful in highlighting which groups of HCWs are most at risk from NSIs.

Key words: $\quad$ HCWs, Health Issue of HCWs, NSI, Needle Stick Injury, NSI in Health Care Workers.

Article Citation: Khan S, Atiq-ur-Rahman, Raza MH, Baig MS, Rasul F, Imran M. Needle Stick Injuries in Healthcare Workers of a Secondar Care Hospital, Pakistan. Professional Med J 2020; 27(3):552-557.

DOI: 10.29309/TPMJ/2020.27.3.3565

\section{INTRODUCTION}

Percutaneous wounds typically set by piercing of needle point in named as Needle Stick Injury (NSI). It may occur by piercing of other sharp objects during working in medical settings. ${ }^{1} \mathrm{NSI}$ is universal issues among figures providing health care services. ${ }^{2} \mathrm{NSI}$ causes arousing distress in $\mathrm{HCW}$ s along with health issues resulting absent of HCW from workplace and effects on efficiency of health care services and resources. ${ }^{3}$ After stress, NSIs are the top health and safety concern of nurses worldwide. ${ }^{4}$ Highest rate of NSIs are reported in nurses among healthcare workers due to their maximum exposure to the needles and other sharp instruments. ${ }^{5}$

NSI occur while working in medical setting and dealing with sharp objects commonly used during health care delivery i.e. IV cannulas, syringes, phelebotomy tools and vaccutainer needle etc. Causes of NSI include many factor i.e. needle design and type, recapping practice, specimen handling, specimen transferring, during waste collection and segregation, during passing, handling and disposing IV line. ${ }^{6}$ Due to lack of expertise, nursing students are at higher risk of $\mathrm{NSI}^{7}$ Risk factor of $\mathrm{NSI}$ includes lack of biosafety knowledge, availability of proper resources and compliance assurance of infection control measures. ${ }^{8}$ As reported, worldwide about two million HCWs got NSI every year. ${ }^{9}$ Different infections which may transfer via NSI include hepatitis $B$ virus (HBV), hepatitis $C$ virus (HCV) and human immuno- deficiency virus (HIV). ${ }^{10,11}$ Other infection which may transfer via NSI includes bacterial, fungal, malarial, syphilis and 
spotted fever. ${ }^{12}$

The rate of infection transmission per NSI is ranging 6-30 percent, 3 percent and 0.3 percent for HBV, HCV and HIV respectively. ${ }^{13,14}$ In developing countries, HBV is serious public health issue. According to estimate by World Health Organization, about 250 million natives are HBV infected worldwide. ${ }^{15}$

Risk factor for sharp injuries is poor practices of standard safety measures which increases NSI risk double. ${ }^{16}$ Probably pressure of workload and constraint of time meant to be cause of NSI, as due to under reporting exact reason is ambiguous. ${ }^{17}$ The incidence of $\mathrm{NSI}$ is considerably higher than current estimates, due to gross underreporting (often less than $50 \%$ ) it is assumed that NSI incidence would be higher than existing estimates, owing to coarse under reporting. ${ }^{18,19}$

\section{METHODOLOGY}

District Headquarter Hospital Layyah is a Secondary Care Hospital having capacity of 344 beds. It was a cross sectional study and there were 161 participants included in this study. Selected HCWs opportunely, comprising of 8 doctors, 129 registered nurses and dispensers, 11 laboratory staff and 13 waste handlers. For study a questionnaire (Structured, pre tested) having both question open and closed ended, used for period Jan-March 2019.

Data analysis software SPSS 23.0 was used for statistical analysis of research data. In descriptive analysis, categorical variables percentages were computed and comparison done by Chi square test. To assess the strength of associations, Odds ratios (ORs) were calculated and confidence intervals (Cls) was $95 \%$, while p-value was $<0.05$, that was statistically significant.

\section{RESULT}

Out of 161 participants, NSIs were radically higher (76.7 \%) in Nursing Staff than Doctors (50\%), Laboratory staff $(45.5 \%)$ and waste handlers $(70.8 \%)$ as shown in (Table-I). It is reported that 114 (70.8\%) HCW participants experienced not less than once NSI during working in healthcare services.

\begin{tabular}{|l|c|c|}
\hline \multicolumn{1}{|c|}{ Workers } & Total No. & $\begin{array}{c}\text { History of NSI } \\
\text { No. \% }\end{array}$ \\
\hline Doctor & 8 & $4(50)$ \\
\hline Nurses/Dispensor & 129 & $99(76.7)$ \\
\hline Laboratory Staff & 11 & $5(45.5)$ \\
\hline Waste Handler & 13 & $6(46.2)$ \\
\hline Total & 161 & $114(70.8)$ \\
\hline
\end{tabular}

Table-I. Distribution of needle sticks injuries among health care.

The maximum no. of NSI reported during phlebotomy or passing IV line/injecting (62\%) subsequently surgical procedures $(21 \%)$ and recapping of syringes or disposing after use $(17 \%)$.

The awareness about transmission risk of HBV, $\mathrm{HCV}$ and HIV by NSI was good among HCWs as doctors, nurses, lab staff and waste handlers (> 92\%). 88\% participants were aware of NSI preventive measures.

94\% of participants reported that they practice use of yellow box while disposing sharps. In response of question about how to prevent NSIs in healthcare facility, $90 \%$ participants suggested to conduct biosafety training.

It is reported in our study that HCWs did not notify the infection control room/office about NSI within 24 hours as mostly participants responded they don't think it is important. It was pleasant aspect of study that HCWs use of PPEs which include use of gloves and sharp container due to implementation of healthcare commission guidelines and active infection control committee. (Table-II)

The key reason identified of $\mathrm{NSI}$ among HCWs participants was inattention (60.9\%) followed by lack of protection measures (37.9\%) and work burdened (1.2\%). 


\begin{tabular}{|c|c|c|c|c|}
\hline Characteristics & $\begin{array}{l}\text { Doctor } \\
\mathrm{N}=8\end{array}$ & $\begin{array}{l}\text { Nurses/Dispensers } \\
\qquad N=129\end{array}$ & $\begin{array}{l}\text { Laboratory Staff } \\
\qquad \mathrm{N}=11\end{array}$ & $\begin{array}{l}\text { Waste Handler } \\
\qquad \mathrm{N}=13\end{array}$ \\
\hline \multicolumn{5}{|l|}{ Incidence of NSI } \\
\hline Yes & 4 & 99 & 5 & 6 \\
\hline No & 4 & 30 & 6 & 7 \\
\hline \multicolumn{5}{|l|}{ No. of NSI Incidence } \\
\hline Once & 2 & 7 & 1 & 1 \\
\hline Twice & 1 & 20 & 2 & 2 \\
\hline More than two & 1 & 72 & 2 & 3 \\
\hline \multicolumn{5}{|l|}{ Post NSI Measures } \\
\hline Allowed to bleed & 4 & 85 & 5 & 5 \\
\hline Reported to incharge & 0 & 2 & 3 & 0 \\
\hline Washed with soap & 3 & 90 & 4 & 2 \\
\hline \multicolumn{5}{|l|}{ Knowledge NSI transmittable diseases } \\
\hline Hepatits B & 8 & 125 & 11 & 3 \\
\hline Hepatits C & 8 & 125 & 11 & 3 \\
\hline HIV & 8 & 120 & 11 & 1 \\
\hline \multicolumn{5}{|l|}{ Practices } \\
\hline Vaccination & 8 & 129 & 7 & 4 \\
\hline Use of PPEs & 8 & 129 & 11 & 13 \\
\hline Use of sharp container & 8 & 129 & 11 & 13 \\
\hline \multicolumn{5}{|l|}{ Strategy for prevention Of NSI } \\
\hline Training of HCWs & 6 & 110 & 8 & 3 \\
\hline Avoiding needle recap & 8 & 120 & 11 & 7 \\
\hline Use of sharp disposal containers & 8 & 129 & 11 & 13 \\
\hline $\begin{array}{l}\text { Avoiding needle breaking/bending by } \\
\text { hand }\end{array}$ & 6 & 111 & 11 & 13 \\
\hline Avoiding leaving open syringes & 8 & 129 & 11 & 13 \\
\hline
\end{tabular}

Table-II. Descriptive characteristics and answers to questions by the participants.

Work Experience in years

\begin{tabular}{|c|}
\hline$<5$ \\
6 to 10 \\
\hline 11 to 15 \\
\hline 16 to 20 \\
above 2 \\
\hline Total
\end{tabular}

Total No.

\begin{tabular}{|c|}
\hline 50 \\
\hline 87 \\
\hline 17 \\
\hline 3 \\
\hline 4 \\
\hline 161 \\
\hline
\end{tabular}

History of NSI No. \%

$25(50)$

$71(81.6)$

$14(82.4)$

$2(66.7)$

$2(50)$

$114(70.8)$

Table-III. Distribution of needle stick injuries as per years of work experience.

\section{DISCUSSION}

This study assesses the prevalence as well as knowledge, attitude and practices of NSIs. Among this study, the prevalence of NSIs (70.8\%) was considerably lower than a study conducted where it was $(77 \%)$ of HCWs reported NSIs during their career in civil hospital Karachi. ${ }^{20}$ A study conducted in Dehli, India on needle stick injury shows alarming percentage $(79.5 \%)$ healthcare workers have at least one NSI, which was similar to study results. ${ }^{21}$ At Alexinderia Hospital, a study was conducted in 2011, in which it is reported that $2 / 3^{\text {rd }}$ of healthcare workers $(67.9 \%)$ in last one year, they had at least one $\mathrm{NSI}^{22}$ But our results were different; we found minimum number of NSIs during last 12 months due to implementation of 
Punjab health care commission guidelines. The study was conducted on NSIs among HCWs at two Malaysian teaching hospitals having lower prevalence $31.6 \%$ and $52.9 \%$ respectively ${ }^{23}$ contradictory from our finding while $29.2 \%$ HCWs were not reported for injury because lack of awareness and knowledge. Underreporting of $\mathrm{NSI}$ is a common problem in our healthcare facilities. A lot of injuries go unreported, they did not think it important or afraid to register as $60.5 \%$ nurses, $5 \%$ lab staff, $1.2 \%$ doctors and $3.1 \%$ waste handler suffered from NSI. A similar study was conducted that reports, $64.7 \%$ doctors did practice of recapping the needle followed by waste handlers, nursing staff as $25.5 \%$ and $7.8 \%$ respectively. ${ }^{24}$ Comparison with other study have shown that $15.2 \%$ and $11.3 \%$ of HCWs reported that they recapped a needle respectively. ${ }^{25} \mathrm{HCWs}$ had been using PPEs like wearing gloves because they are trained and aware of biosafety, here no injury occurs by this. Use of Personal protective equipment i.e. gloves is meant to be an first line of defense against NSIs. A study reported by Sharma in 2010 about awareness of biosafety practices in HCWs was so high and only $1.2 \%$ HCWs experienced NSI. ${ }^{26}$

Similar finding had been reported in a study ${ }^{27}$, participants who had received three doses, two doses or one dose of HBV vaccine comprised $82.6 \%, 11.4 \%$ and $1 \%$ of the vaccinated individuals, respectively. $5 \%$ participants were not vaccinated. Antibodies for Hepatitis B after vaccination have not been checked.

In Karachi, the largest metropolis of Pakistan, the prevalence of hepatitis B between garbage scavengers was $18.8 \% .^{28}$ Therefore, measures should be put in place to ensure that all HCWs have access to aワordable hepatitis B immunization and good coverage rates are achieved amongst all groups of workers. As no vaccine available for HCV and HIV infections and treatment for these health issue is also expensive. When the infection at chronic phase then sudden end of $\mathrm{HCV}$ is infrequent. Affected people have liver fibrosis because of chronic hepatitis $\mathrm{C}$, after 10 to 40 years cirrhosis start in $15-25 \%$ of patients and they are at high risk of liver failure and hepatocellular carcinoma. ${ }^{29}$ It is essential that HCWs continue to be aware of the importance of developing good practice to avoid NSI. The possible way to stay protected from NSIs is to be aware about safe practices and use of PPEs.

\section{CONCLUSION}

In Pakistan, there is high frequency of NSIs in medical facilities, but data shows low frequency due to under reporting. Small data study like this study can be useful for highlighting the groups which are prone to high risk of NSI. It can also be useful in policy formulation of organizational biosafety measures.

\section{Conflict of Interest}

The authors have no conflict of interest.

\section{Copyright $(13$ Dec, 2019.}

\section{REFERENCES}

1. https://en.wikipedia.org/wiki/Needlestick_injury. Retrived on March 2019.

2. Atenstaedt RL, Payne S, Roberts RJ, Russell IT, Russell $D$, Edwards RT. Needle-stick injuries in primary care in Wales. Journal of public health. 2007 Dec 1;29(4):43440.

3. Sharma R, Rasania SK, Verma A, Singh S. Study of prevalence and response to needle stick injuries among health care workers in a tertiary care hospital in Delhi, India. Indian journal of community medicine: official publication of Indian Association of Preventive \& Social Medicine. 2010 Jan;35(1):74.

4. Clark PF, Clark DA. World survey of nurses unions and associations: Preliminary report. Hershey, PA: Penn State University, 2000.

5. Medicalkenya. Nursing matters - WHO fact sheets. Nairobi: Medicalkenya; 2011.

6. Wilburn SQ. Needlestick and sharps injury prevention. Online journal of issues in nursing. 2004 Sep 30;9(3):5.

7. Verma Y, Bandlish D, Kumar B. The prevalence of needle sticks injury among healthcare personnel in a tertiary care hospital in Kolkata. Webmed Central Clinical Microbiology. 2015;6(9).

8. Zungu, L.I., Sengane, M., Setswe, K.G., 2008. Knowledge and experiences of needle prick injuries (NPI) among nursing student Sata University in Gauteng, South Africa. S. Afr. Fam. Pract. 50 (5) (4848c). 
9. World Health Organization-WHO, "Occupational health, needle stick injuries," 2016,http://www.who. int/occupational_health/topics/need injuries/en/.

10. National Health Services-NHS, "What should I do if I injure myself with a used needle?" 2015, http://www. nhs.uk/chq/ Pages/2557.aspx? CategorylD72.

11. Smith AJ, Cameron SO, Bagg J, Kennedy D. Management of needlestick injuries in general dental practice. British dental journal. 2001 Jun;190(12):64550.

12. Canadian Centre for Occupational Health and Safety CCOHS, "Needle stick and sharps injuries," 2015, http://www. ccohs. ca/osh answers/diseases/ needlestick_injuries.html.

13. Elmiyeh B, Whitaker I, James M, Chahal C, Galea A, Alshafi $K$. Needle-stick injuries in the national health service: A culture of silence. J Royal Society Med. 2004; 97(7):326-27.

14. Shoghli A, MousaviNasab N, Ghorchian F, Masoumi H, Momtazi S. Study of the needle sticks injury (NSI) among the Zanjan Educational Hospitals Staff. ZUMS J. 2013; $21(85): 131-41$.

15. Klein G, Botelho TK, de Cordova CM, do Livramento A. High prevalence of HBV carriers among waste collectors in the largest landfill in Latin America. Revista De Patologia Tropical/Journal of Tropical Pathology. 2018 Mar 29;47(1):5-10.

16. Jacob A, Newson-Smith M, Murphy E, Steiner M, Dick F. Sharps injuries among health care workers in the United Arab Emirates. Occupational medicine. 2010 Aug 1;60(5):395-7.

17. Clarke SP, Sloane DM, Aiken LH. Effects of hospital staffing and organizational climate on needlestick injuries to nurses. American journal of public health. 2002 Jul;92(7):1115-9.

18. Makary MA, Al-Attar A, Holzmueller Cg, Sexton JB, Syin $D$, gilson $M M$, et al. Needle stick injuries among surgeons in training. N Engl J Med 2007; 356: 2693-9.

19. Au E, gossage JA, Bailey SR. The reporting of needle stick injuries sustained in theatre by surgeons: are we underreporting? J Hosp Infect 2008; 70: 66-70.
20. Rais N, Jamil HM. Prevalence of needle stick injuries among health care providers. Int $\mathrm{J}$ Endorsing Health Sci Res. 2013 Dec;1(2):73-9.

21. Sharma R, Rasania SK, Verma A, Singh S. Study of prevalence and response to needle stick injuries among health care workers in a tertiary care hospital in Delhi, India. Indian journal of community medicine: official publication of Indian Association of Preventive \& Social Medicine. 2010 Jan;35(1):74.

22. Hanafi MI, Mohamed AM, Kassem MS, Shawki M. Needlestick injuries among health care workers of University of Alexandria Hospitals. EMHJ-Eastern Mediterranean Health Journal, 17 (1), 26-35, 2011. 2011.

23. $\mathrm{Ng}$ YW, Hassim IN. Needlestick Injury Among Medical Personnel in Accident and Emergency Department of Two Teaching Hospital. Medical Journal of Malaysia. 2007 Mar;62(1):9.

24. Rais N, Jamil HM. Prevalence of needle stick injuries among health care providers. Int J Endorsing Health Sci Res. 2013 Dec;1(2):73-9.

25. Kakizaki M, Ikeda N, Ali M, Enkhtuya B, Tsolmon M, Shibuya K, Kuroiwa C. Needlestick and sharps injuries among health care workers at public tertiary hospitals in an urban community in Mongolia. BMC research notes. $2011 \mathrm{Dec}$ 1;4(1):184.

26. Sharma R, Rasania SK, Verma A, Singh S. Study of prevalence and response to needle stick injuries among health care workers in a tertiary care hospital in Delhi, India. Indian journal of community medicine: official publication of Indian Association of Preventive \& Social Medicine. 2010 Jan;35(1):74.

27. Malik A, Shaukat MS, Qureshi A. Needle-stick injury: A rising bio-hazard. Journal of Ayub Medical College Abbottabad. 2012 Dec 1;24(3-4):144-6.

28. Klein G, Botelho TK, de Cordova CM, do Livramento A. High prevalence of HBV carriers among waste collectors in the largest landfill in Latin America. Revista De Patologia Tropical/Journal of Tropical Pathology. 2018 Mar 29;47(1):5-10.

29. Sahrish Khan et al., Risk factors of hepatitis C In District Layyah, Indo Am. J. P. Sci, 2019; 06(01). 


\begin{tabular}{|c|c|c|c|}
\hline \multicolumn{4}{|c|}{ AUTHORSHIP AND CONTRIBUTION DECLARATION } \\
\hline Sr. \# & Author(s) Full Name & Contribution to the paper & Author(s) Signature \\
\hline 1 & Sahrish Khan & $\begin{array}{l}\text { Conception, Planning of } \\
\text { research, Data collection. }\end{array}$ & \\
\hline 2 & Atiq-ur-Rahman & $\begin{array}{l}\text { Conception, Planning of } \\
\text { research, Data collection. }\end{array}$ & Hean \\
\hline 3 & Muhammad Hashim Raza & $\begin{array}{l}\text { Data analysis, Interpretation, } \\
\text { Writing of manuscript. }\end{array}$ & \\
\hline 4 & Muhammad Safdar Baig & Proof reading. & \\
\hline 5 & Faiz Rasul & Help in references. & Fain Pasen \\
\hline 6 & Muhammad Imran & $\begin{array}{l}\text { Data analysis, Interpretation, } \\
\text { Writing of manuscript. }\end{array}$ & \\
\hline
\end{tabular}

